\title{
Estudo Fotofísico do Cromóforo p-fenóxi-metil-estilbeno Livre ou Ligado a um Esqueleto de Poliestireno.
}

\author{
Marcelo Aguiar, Shu Hui Wang, Frank E. Karasz e Leni Akcelrud
}

\begin{abstract}
Resumo: O comportamento fotofísico do cromóforo p-fenóxi-metil-estilbeno livre ou como grupamento pendente em cadeia polimérica foi estudado através de espectros de absorção e fotoluminescência em solução e no estado sólido. As características do cromóforo livre foram observadas usando-se o composto modelo p-(petil-fenóximetil)estilbeno e as do cromóforo ligado a um esqueleto polimérico foram estudadas com o poli(estireno-co-estilbenil-p-metoxiestireno). Os resultados são interpretados em termos de emissões provenientes do cromóforo isolado ou de agregados formados no estado fundamental
\end{abstract}

Palavra-chave: Cromóforo, estilbeno, poliestireno, fotoluminescência

\section{Introdução}

Os polímeros conjugados têm sido objeto de crescente interesse científico e tecnológico desde a década de 70, quando apareceram os polímeros semicondutores. A partir de então, novas propriedades físicas foram descobertas, tais como as propriedades óticas não-lineares e a eletroluminescência ${ }^{[1]}$. Esta ultima caracteriza-se pela emissão de luz quando o polímero é submetido à passagem da corrente elétrica. A primeira estrutura polimérica eletroluminescente foi descoberta em 1990 pelo grupo de Cambridge, na Inglaterra, que observou a emissão de luz verde-amarelada pelo poli(fenileno-vinileno) (PPV) ${ }^{[2]}$. Atualmente, já nos encontramos no estágio onde já é possível obter emissão, através de polímeros, em todos os comprimentos de onda do espectro visível, variando a estrutura polimérica em dispositivos emissores de luz (LEDs) ${ }^{[3]}$. A grande vantagem dos LEDs poliméricos em relação aos inorgânicos tradicionais reside na pos- sibilidade de construção de mostradores de grande superfície. Compostos orgânicos de baixo peso molecular contendo cromóforos também foram usados para a fabricação destes dispositivos, e em principio uma ampla gama de cores de emissão pode ser obtida, mas estes materiais tendem a cristalizar, prejudicando o contato com os eletrodos. Além disso, requerem altas voltagens para a injeção de cargas, limitando a sua aplicação. Avanços recentes, tais como a deposição á vácuo de camadas transportadoras de carga amorfas, separando os materiais cristalinos dos eletrodos ${ }^{[3-7]}$ ou dispersando os produtos em matriz polimérica de poli(metacrilato de metila) ou policarbonato ${ }^{[8,9]}$ formando solução sólida, representam soluções parciais para estes problemas. Pelos motivos acima mencionados, compreende-se por que o uso de polímeros intrinsecamente emissores é altamente desejável, já que permitem a combinação de outras boas propriedades com a emissão, tais como, a capacidade de formar filme, estabilidade dimensional e química.

Marcelo Aguiar - Instituto de Química, UFRJ; Shu-Hui Wang - Centro de Ciências e Tecnologia, UENF; Frank E. Karasz-Department of Polymer Science and Engineering, UMASS e Leni Akcelrud -Instituto de Macromoléculas Professora Eloisa Mano, UFRJ, Ilha do Fundão, Cx Postal 68525, CEP 21945-970, Rio de Janeiro, RJ. 
O comprimento de onda da emissão depende do tamanho de banda de decaimento (band gap) dos excitons formados pela passagem da corrente elétrica, do estado excitado para o estado fundamental, e que por sua vez, varia com a estrutura eletrônica do sítio emissor (cromóforo) ${ }^{[2-17]}$. Assim a sintonia da cor pode ser feita variando-se a estrutura química do polímero. Quando se deseja obter um deslocamento hipsocrómico de emissão por exemplo, a estratégia sintética consiste no confinamento da conjugação no polímero, o que pode ser feito de várias maneiras, tais como inserção de ligações meta ou pela imposição de distorções estéricas na cadeia $^{[18,19]}$ em polímeros aromáticos completamente conjugados, tais como polifenilenos substituídos. Outra possibilidade é a separação dos cromóforos por espaçadores não emissivos formando os copolímeros do tipo conjugado - não conjugado ${ }^{[20-23]}$. Neste caso o confinamento da emissão ficou provado pela independência de cor em relação ao tamanho do espaçador ${ }^{[21]}$. Uma outra estratégia consiste na inserção de cromóforos à uma cadeia principal não emissiva, e dentro deste ponto de vista foram sintetizados polímeros onde cromóforos do estilbeno se encontram graftizados a um esqueleto de poliestireno ${ }^{[24-28]}$.

Como a fotoluminescência é uma condição necessária para a eletroluminescência, medidas de absorção ótica e fotoluminescência são comumente empregadas para o estabelecimento das correlações entre a natureza do centro emissor e as propriedades emissivas correlatas. Na presente comunicação são apresentados alguns resultados referentes à fotofísica do poli(estireno-co-estilbenil-p-metoxiestireno) (Esquema 1A), e uma interpretação das suas características foto e eletroluminescente. O centro emissor também foi estudado separadamente, através do composto modelo p-(p-etilfenoximetil)estilbeno (Esquema 1B)

\section{Experimental}

Foi empregada a condensação de Williamson para a preparação do poli(estireno-co-estilbenil-pmetoxiestireno) (Esquema 1A), através da reação do precursor poli(estireno-co-acetóxiestireno) com o pclorometilestilbeno. A razão molar entre os comonômeros estireno e p-acetoxiestireno foi acertada para a obtenção de composição 1:1 aleatoriamente distribuída. A caracterização do precursor e do polímero final foi feita através de RMN, FTIR, GPC, DSC e análise elementar. O espectro no
A

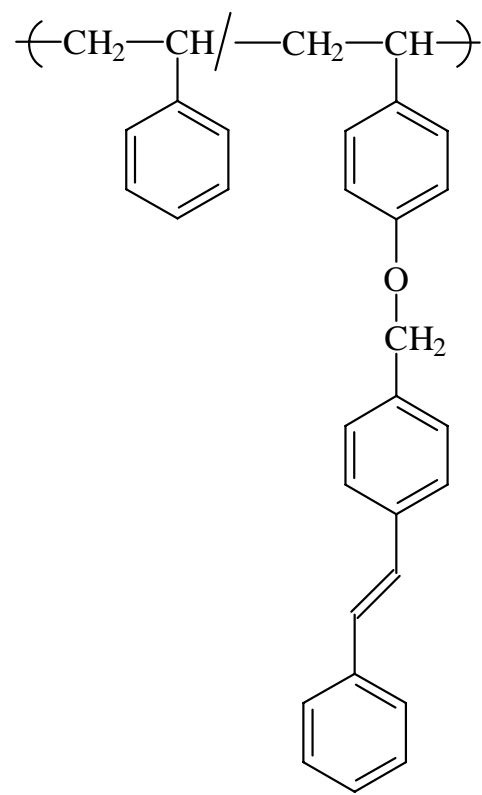

Esquemas
B<smiles>CCc1ccc(OCc2ccc(/C=C/c3ccccc3)cc2)cc1</smiles>

$1 \mathrm{~B}$

infravermelho do polímero emissor indicou desaparecimento completo da carbonila, caracterizando total substituição dos grupamentos acetóxi do precursor. Os resultados de GPC acusaram aumento da massa molecular correspondente ao aumento da massa molecular do mero substituído. Estes dados foram corroborados pela análise elementar.

Os dados referentes às reações e às análises encontram-se descritos em detalhe nas referências 24-26.

\section{Resultados e Discussão}

O poli(estireno-co-estilbenilmetoxiestireno) foi obtido através de substituição dos grupamentos pacetóxi do poli(estireno-co-acetoxiestireno). Este precursor foi escolhido porque o par estireno (1)/ p-acetóxiestireno ${ }^{[2]}$ reúne características importantes, tais como, razões de atividade adequadas para uma distribuição aleatória dos comonômeros $\left(\mathrm{r}_{1}=0,85 \mathrm{e}\right.$ $\mathrm{r}_{2}=1,3$ ), o acetóxi é um bom grupamento de saída para a condensação de Williamson, e o grau de substituição pode ser acompanhado pelo desaparecimento da absorção da carbonila no infravermelho.

A Figura 1 mostra os espectros de absorção do composto modelo (a) e do copolímero (b e c). Tanto o composto modelo como o copolímero apresentam uma forte absorção centrada a $320 \mathrm{~nm}$, mas somente o copolímero apresenta outra banda, centrada a $360 \mathrm{~nm}$, a qual se apresenta melhor resolvida em solução (c). 


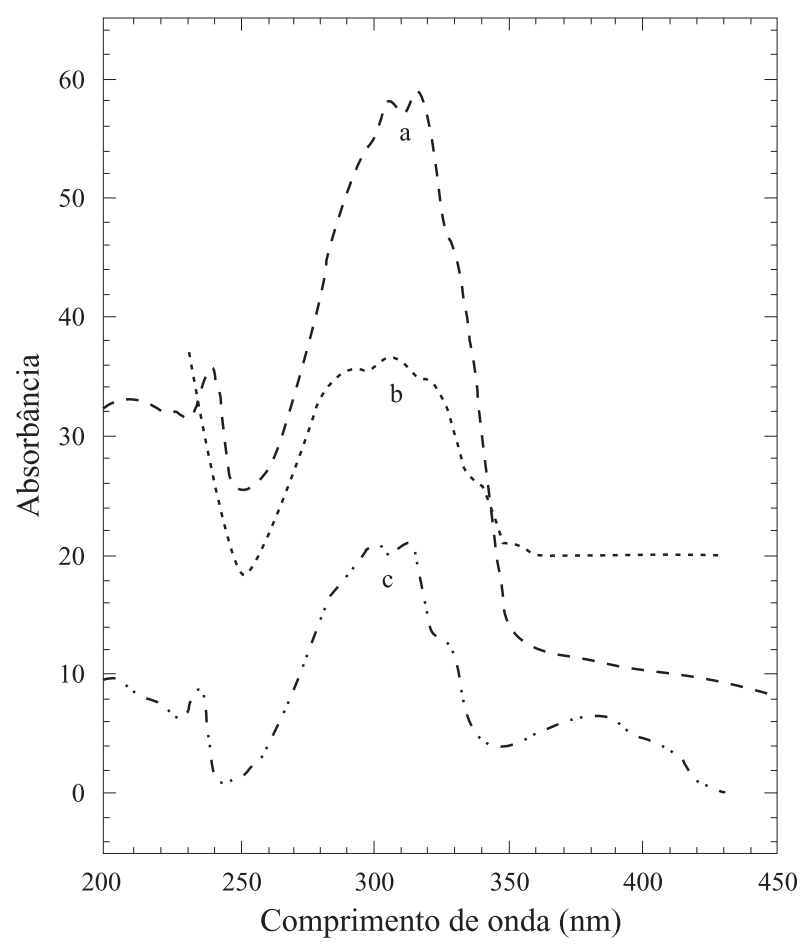

Figura 1. Espectros de absorção no ultravioleta. (a) composto modelo em clorofórmio a 1 X $10^{-5} \mathrm{M}$, (b) filme sólido do copolímero poli(estirenoco-estilbenil-p-metoxiestireno) e (c) copolímero poli(estireno-co-estilbenilp-metoxiestireno) em clorofórmio a 1 X $10^{-5} \mathrm{M}$.

É importante observar neste ponto que a concentração total dos cromóforos estilbênicos é a mesma para o composto modelo e para o copolímero $\left(10^{-5} \mathrm{M}\right)$.

O comportamento fotofísico do composto modelo e do copolímero apresentam características não usuais para este tipo de sistema, isto é, dependem da concentração e do comprimento de onda de excita-

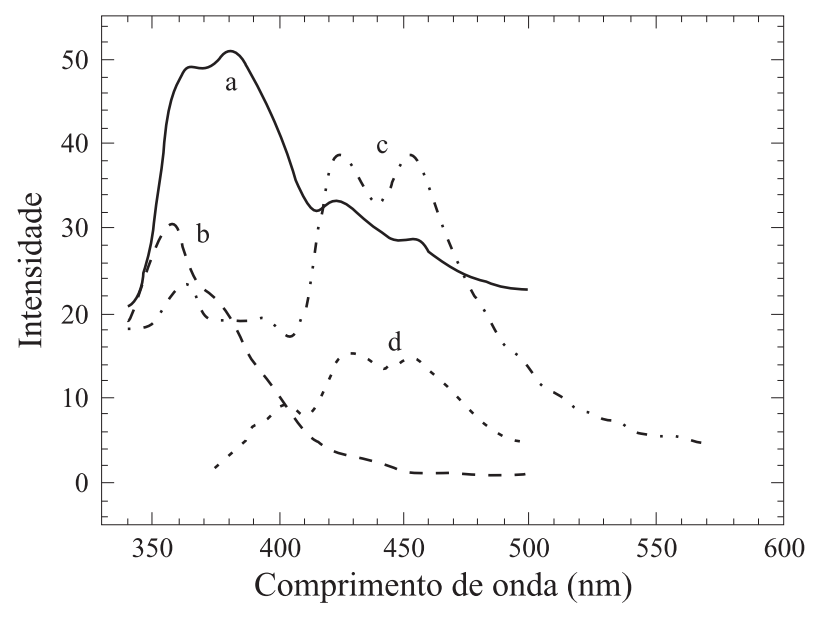

Figura 2. Espectros de fluorescência após excitação a $\lambda=320 \mathrm{~nm}$. (a) composto modelo em clorofórmio a $5 \times 10^{-4} \mathrm{M}$, (b) trans-estilbeno em clorofórmio a $10^{-5} \mathrm{M}$, (c) copolímero poli(estireno-co-estilbenil-pmetoxiestireno) em tolueno a $1 \times 10^{-4} \mathrm{M}$ e (d) composto modelo em clorofórmio a 1 X $10^{-2} \mathrm{M}$.

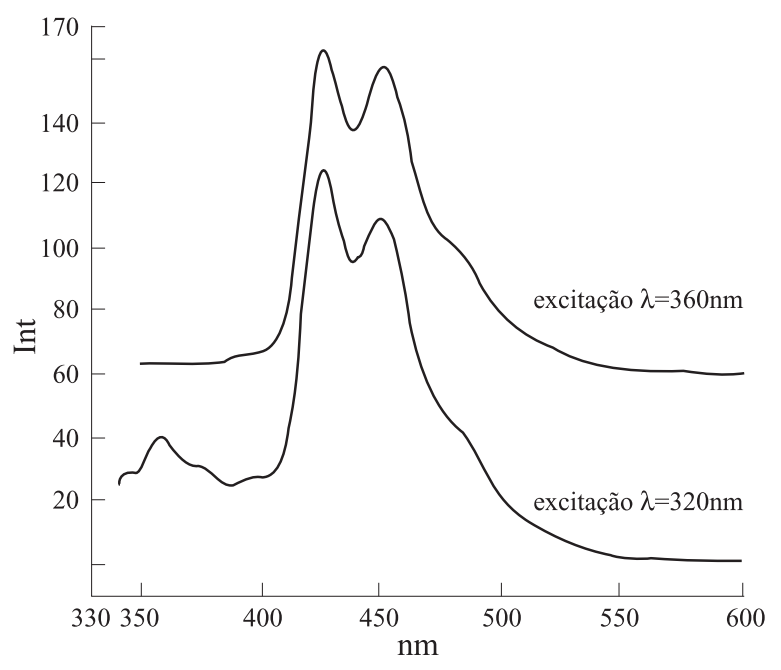

Figura 3. Espectros de fluorescência do copolímero em clorofórmio a $10^{-5} \mathrm{M}$ após excitação a diferentes comprimentos de onda.

ção $(\lambda)$, conforme pode ser verificado pelo espectro das Figuras 2 e 3. Na Figura 2, para a irradiação a $\lambda=320 \mathrm{~nm}$, a fluorescência do composto modelo na concentração de $1 \mathrm{X} 10^{-4} \mathrm{M}$ (a) é consistente com

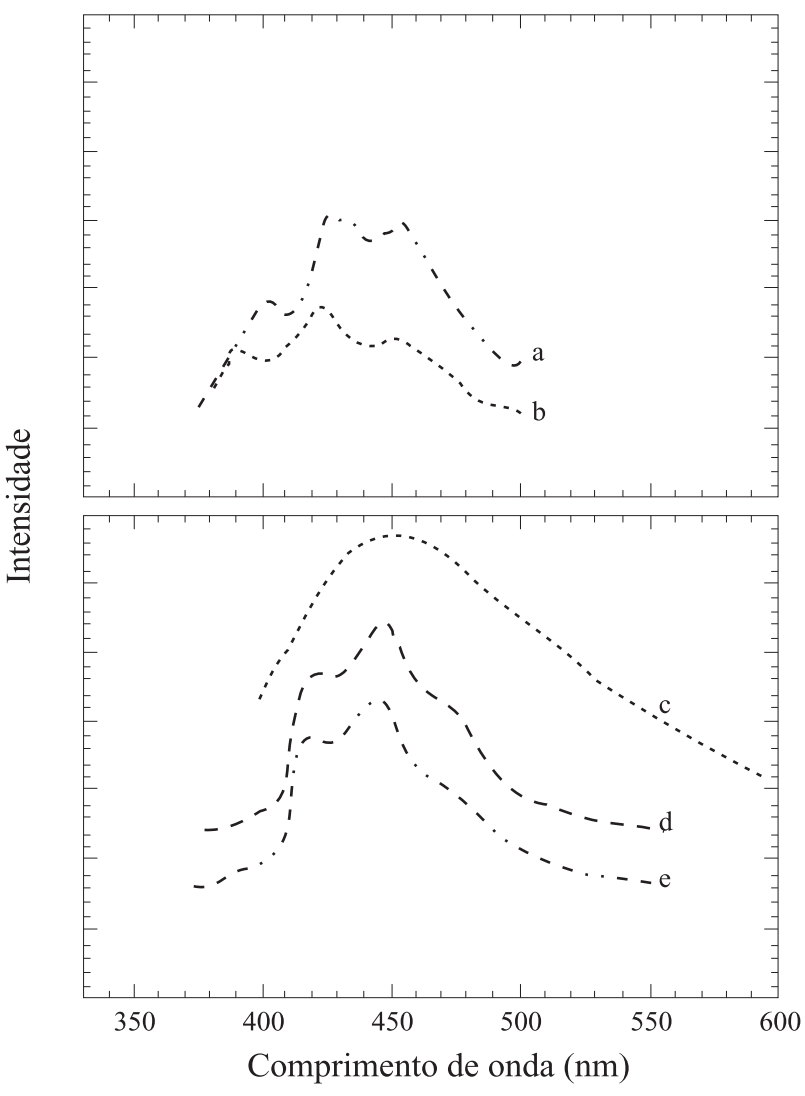

Figura 4. Espectros de fluorescência. Composto modelo em clorofórmio: (a) a $1 \times 10^{-2} \mathrm{M}$ excitado com $1=320 \mathrm{~nm}$ e (b) a $1 \times 10^{-2} \mathrm{M}$ excitado $\operatorname{com} \lambda=360 \mathrm{~nm}$. Filme sólido do copolímero poli(estireno-co-estilbenilp-metoxiestireno): (c) eletroluminescência, (d) excitado com $\lambda=360$ nm e (e) excitado $\operatorname{com} \lambda=320 \mathrm{~nm}$. 
a do trans-estilbeno (b), mostrando que os centros emissores na região de $360 \mathrm{~nm}$ são as unidades estilbênicas. O copolímero (c) também emite nesta região, mas adicionalmente apresenta outra série de bandas centradas a $440 \mathrm{~nm}$. O composto modelo quando em concentrações elevadas $\left(10^{-2} \mathrm{M}\right)(\mathrm{d})$ também apresenta estas novas bandas. $\mathrm{O}$ comprimento de onda de $320 \mathrm{~nm}$ foi escolhido para irradiação porque corresponde à primeira banda de absorção (Figura 1) e também ao máximo de intensidade de emissão em $360 \mathrm{~nm}$, conforme será visto mais adiante. Os resultados das Figuras 1 e 2 indicam que a absorção a $320 \mathrm{~nm}$ e a emissão a $360 \mathrm{~nm}$ correspondem ao cromóforo estilbeno.

Quando o comprimento de onda de excitação é $\lambda=360 \mathrm{~nm}$, que corresponde à segunda banda de absorção do copolímero (Figura 1), a fotoluminescência apresenta-se completamente diferente daquela verificada quando $\lambda=320 \mathrm{~nm}$. Neste caso, as emissões centradas a $360 \mathrm{~nm}$ desaparecem, e tanto o composto modelo como o copolímero passam a emitir somente na região em torno de $440 \mathrm{~nm}$, conforme pode ser visto na Figura 3, que apresenta os espectros de emissão do copolímero após excitação nos dois comprimentos de onda.

Conforme mencionado anteriormente, soluções a $10^{-4} \mathrm{M}$ do composto modelo em clorofôrmio emitem a $360 \mathrm{~nm}$ quando irradiada a $\lambda=320 \mathrm{~nm}$ (Figura 2a). No entanto, quando a concentração é aumentada para $10^{-2} \mathrm{M}$ a emissão passa a ocorrer na região de $440 \mathrm{~nm}$, e o espectro se torna idêntico ao de soluções irradiadas a $\lambda=360 \mathrm{~nm}$, a qualquer concentração, conforme pode ser verificado pela observação das curvas (a) e (b) da Figura 4.

A análise dos resultados experimentais acima descritos conduz à conclusão de que existe mais de um centro emissor, embora exista somente um único tipo de cromóforo por molécula do composto modelo, ou ainda por unidade repetitiva no copolímero. Assim sendo, além da emissão dos centros estilbênicos isolados, uma segunda emissão é originada por sistema de agregados de moléculas, provavelmente a maior parte na forma dimérica. $\mathrm{O}$ fato de que somente o copolímero absorve a $360 \mathrm{~nm}$ (Figura 1) leva-nos a propor que esta banda é originada por dímeros ou agregados de maior ordem, formados no estado fundamental, e que são responsáveis por emissões nos comprimentos de onda maiores. Quando ligados ao esqueleto polimérico a concentração localizada dos cromóforos é muito maior do que no estado livre (composto modelo), devido a imposições conformacionais presentes no esqueleto polimérico.
Assim, o número de associações intramoleculares entre cromóforos será muito maior do que o encontrado no estado não ligado. Entretanto, a presença de agregados no composto modelo em solução é evidente em concentrações elevadas, como mostra a curva (d) da Figura 2 , onde a concentração é $10^{-2} \mathrm{M}$.

No estado sólido a agregação das unidades cromofóricas atinge um número tal que a emissão monomérica é suprimida, para qualquer comprimento de onda de excitação, conforme pode ser visto nas curvas (d) e (e) da Figura 4. Como o espectro de eletroluminescência é consistente com o de fotoluminescência no estado sólido, conclui-se que a eletroluminescência é gerada pelos agregados cromofóricos.

Estes resultados também estão presentes na (Figura 5), onde um gráfico tridimensional combina o espectro de emissão com o espectro de excitação. Assim, a intensidade das bandas referentes a emissão do cromóforo isolado e aos agregados fica relacionada simultaneamente com os comprimentos de onda da luz incidente e da luz emitida.

É interessante notar que a observação de agregados emissores pode ser encontrada em polímeros vinílicos

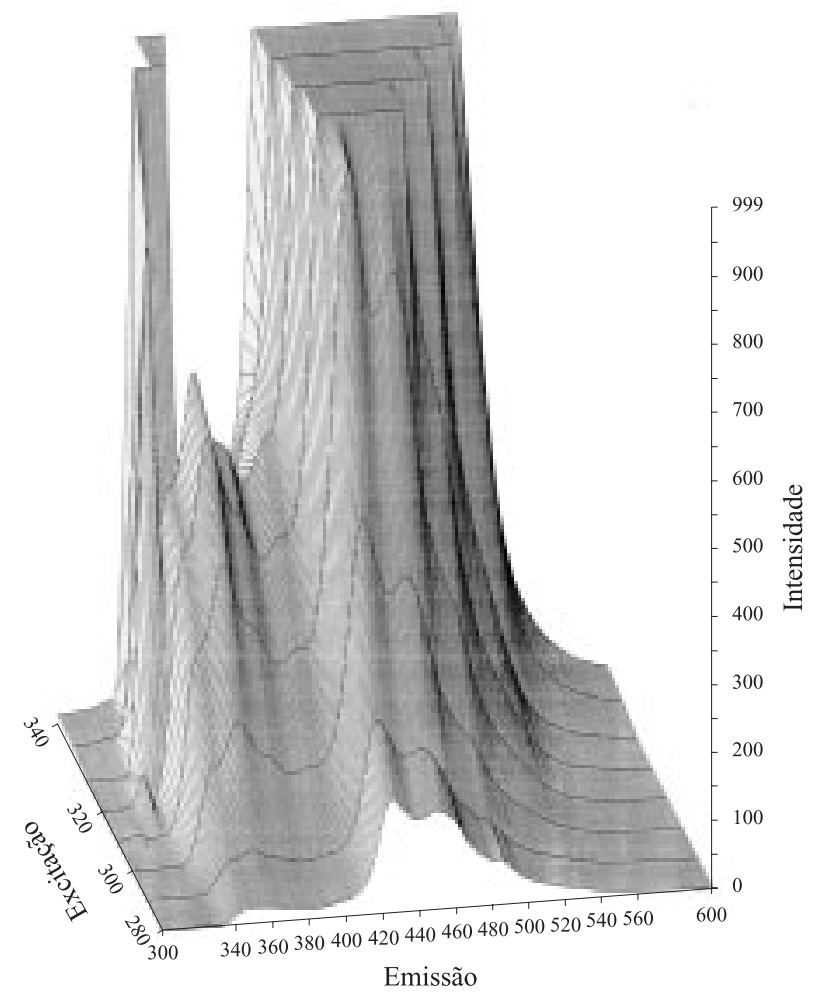

Figura 5. Espectro tridimensional de copolímero poli(estireno-coestilbenil-p-metoxiestireno) em clorofórmio a $1 \times 10^{-5} \mathrm{M}$, mostrando o espectro de emissão em função do comprimento de onda da excitação. 
com substituintes aromáticos formando excímeros, tais como, poliestireno ou poli (1-vinil naftaleno) ${ }^{[29]}$. Estes excímeros foram observados em várias condições, e sempre apresentam uma banda de emissão a comprimentos de onda maiores comparados àqueles relativos ao cromóforo isolado. Este deslocamento é atribuído ao fato de que excímeros se formam pela interação de um cromóforo excitado $\left(\mathrm{M}^{*}\right)$ com outro no estado fundamental (M) formando uma entidade dupla [(MM)*] de mais baixa energia. No presente estudo, os agregados se formam já no estado fundamental (MM), conforme espectros de absorção no ultravioleta apresentados na Figura 1. Assim, unidades diméricas (MM) são promovidas para nível excitado, formando espécies (MM)*. Isto, no entanto não exclui a possibilidade de formação de excímeros pelo mecanismo clássico.

\section{Agradecimentos}

M.Aguiar agradece à CAPES; S.H.Wang (processo $n^{\circ}$ 201270/92-7-NV) e L.Akcelrud agradecem ao CNPq e F.E.Karasz agradece à Força Aérea Americana (United States Air Force Office of Scientific Research) pelo apoio financeiro.

\section{Referências Bibliográficas}

1. Akcelrud, L - Rev. Bras. Quim. Ind., jul/set (n $\left.\mathrm{n}^{\mathrm{o}} 701\right)$, 20, (1995).

2. Burroughes, J.H.; Bradley, D.D.C.;Brown, A.R.; Marks, R.N.; Mackay, K.; Friend, R.H.; Burns, P.L.; Holmes, A.B., Nature, 347, 539, (1990).

3. Adachi, C; Tokito, S.;Tsutsui, T.; Saito, S., Jpn. J. Appl.Phys, 27, 269, (1988).

4. Adachi, C; Tsutsui, T.; Saito, S., Appl. Phys. Lett, 55, 1489, (1989).

5. Adachi, C; Tsutsui, T.; Saito, S., Appl. Phys. Lett, $56,799,(1990)$.

6. Tang, C. W.; Vanslyke, S.A., Appl. Phys. Lett., 51, 913, (1987).

7. Tang, C. W.; Vanslyke, S.A., Appl. Phys. Lett., 65, 3610, (1989).

8. Kido, J.; Kohda, M.; Okuyama, K.; Nagai, K., Appl. Phys. Lett. , 61, 761, (1992).

9. Kido, J.; Hongawa, K.; Kohda, M.; Nagai, K.; Okuyama, K., Jpn. J. Appl. Phys., 31, L962, (1992).
10. Burns, P.L.; Holmes, A.B.; Kraft, A.; Bradley, D.D.C.;Brown, A.R; Friend, R.H., J.Chem. Soc., Chem. Commun., 32, (1992).

11. Burns, P.L.; Holmes, A.B.; Kraft, A.; Brown, A.R.; Bradley, D.D.C.; Friend, R.H.; Gymer, R.W., Nature, 356, 47, (1992). Doi, S.; Kuwabara, M.; Noguchi, T.; Ohnishi, T., Synth. Met., 55-57, 4174, (1993).

12. Braun, D.; Heeger, A., J. Appl. Phys. Lett., 58 , 1982, (1991).

13. Braun, D.; Heeger, A.J.; Kroemer, H.J., J. Electron. Mater., 20 , 945, (1991).

14. Ohmori, Y.; Uchida, M.; Muro, K.; Yoshino, K., Jpn. J. Appl. Phys., 30, L1938, (1991).

15. Ohmori, Y.; Uchida, M.; Muro, K.; Yoshino, K., Solid State Commun., 80, 605, (1991).

16. Braun, D.; Gustafsson, G.; McBranch, D.; Heeger, A., J. Appl. Phys., 72, 564, (1992).

17. Greenham, N. C.; Brown, A.R.; Bradley, D.D.C.; Friend, R.H., Synth. Met., 55-57, 4134, (1993).

18. Musfeldt, J.L.; Reynolds, J.R.; Taner, D.B.; Ruiz, J.P.; Wang, J.; Pemerantz, M., J. Appl. Polym. Sci., 32, 2395, (1994).

19. Leising, G.; Grem, G.; Scherf, U., Anais do $2^{\circ}$ Congresso Brasileiro de Polímeros, São Paulo, SP, 569, (1993).

20. Hu, B.; Karasz, F.E.; Morton, D. C.; Sokolik, I; Yang, Z., J. Lumin., 60-61, 919, (1994).

21. Yang, Z.; Sokolik, I;. Hu, B.; Karasz, F.E., Polym. Mater. Sci. Eng., 69, 155, (1993).

22. Yang, Z.; Sokolik, I;. Karasz, F.E., Macromolecules , 26, 1188, (1993).

23. Sokolik, I; Yang, Z.; Karasz, F.E., J. Appl. Phys., 74, 3584, (1993).

24. Aguiar, M; Karasz, F.E.; Akcelrud, L., Macromolecules, 28, 4598, (1995).

25. Aguiar, M; Hu, B.; Karasz, F.E.; Akcelrud, L., Macromolecules, 29, 3161, (1996).

26. Aguiar, M; Hu, B.; Karasz, F.E.; Akcelrud, L., Macromolecules, no prelo, (1997).

27. Aguiar, M; Akcelrud, L.; Karasz, F.E., Synth. Met., 71, 2187, (1995).

28. Aguiar, M; Akcelrud, L.; Karasz, F.E., Synth. Met., 71, 2189, (1995).

29. Fox, R.B.; Price, T.R.; Cozzens, R.F.; McDonald, J.R., J. Chem. Phys., 57, 534, (1972). 